\title{
Benefits and adverse events of melatonin use in the elderly (Review)
}

\author{
LUCREȚIA ANGHEL $^{1 *}$, LILIANA BAROIU ${ }^{1}$, CORINA RIȘCĂ POPAZU $^{1 *}$, DIANA PĂTRAȘ ${ }^{2}$, SILVIA FOTEA $^{1}$, \\ ALEXANDRU NECHIFOR ${ }^{1,3^{*}}$, ANAMARIA CIUBARA ${ }^{1}$, LUIZA NECHITA ${ }^{1}$, CARMINA LIANA MUȘAT ${ }^{4}$, \\ IOANA ANCA STEFANOPOL ${ }^{4}$, ALIN LAURENȚIU TATU ${ }^{1,3,5}$ and ALEXANDRU BOGDAN CIUBARA ${ }^{4}$ \\ ${ }^{1}$ Clinical Medical Department, Faculty of Medicine and Pharmacy, 'Dunărea de Jos' University, 800008 Galați; \\ ${ }^{2}$ Internal Medicine Department, St. Andrew The Apostle Clinical Emergency County Hospital, 800578 Galați; \\ ${ }^{3}$ Multidisciplinary Integrated Center of Dermatological Interface Research, ${ }^{4}$ Department of Morphological and \\ Functional Sciences, Faculty of Medicine and Pharmacy; ${ }^{5}$ Research Center in The Field of Medical and \\ Pharmaceutical Sciences, ‘Dunărea de Jos’ University, 800008 Galați, Romania
}

Received September 3, 2021; Accepted October 5, 2021

DOI: $10.3892 / \mathrm{etm} .2022 .11142$

\begin{abstract}
Melatonin is a hormone secreted by the pineal gland in accordance with the circadian rhythm when the light level decreases. Reduction of melatonin secretion with age may be associated with physiological aging in neurodegenerative diseases by affecting the suprachiasmatic nucleus or of the neuronal pathways of transmission to the pineal gland. A significant decrease in melatonin synthesis has been reported in various disorders and diseases, including cardiovascular diseases, metabolic disorders (particularly diabetes type 2), cancer and endocrine diseases. In addition to the fact, that melatonin is a sleep inducer, it also exerts cytoprotective properties as an antioxidant and free radical scavenger. The therapeutic role of melatonin has been demonstrated in sleep disorders, eye damage and cardiovascular disease. The association between melatonin and $\beta$-blockers has had a positive impact on sleep disorders in clinical trials. Previous studies have reported the anti-inflammatory effect of melatonin by adjusting levels of pro-inflammatory cytokines, including interleukin (IL)-6, IL-1 $\beta$ and tumor necrosis factor- $\alpha$. Melatonin treatment has been demonstrated to decrease IL-6 and IL-10 expression levels and efficiently attenuate T-cell proliferation. Currently, there is an inconsistency of scientific data regarding the lowest optimal dose and
\end{abstract}

Correspondence to: Dr Liliana Baroiu or Dr Luiza Nechita, Clinical Medical Department, Faculty of Medicine and Pharmacy, 'Dunărea de Jos' University, 35 A.I. Cuza Street, 800008 Galați, Romania

E-mail: lilibaroiu@yahoo.com

E-mail: nechitaluiza2012@yahoo.com

${ }^{*}$ Contributed equally

Key words: melatonin, elderly, benefits, safety, long-term use safety of melatonin for long-term use. The aim of the present review was to summarize the evidence on the role of melatonin in various clinical conditions and highlight the future research in this area.

\section{Contents}

1. Introduction

2. Literature review methodology

3. Melatonin physiology

4. Dosage and side effects of melatonin

5. Melatonin and insomnia

6. Melatonin and skin ageing

7. Melatonin and UV protection

8. Melatonin and Bateman purpura

9. Melatonin and hypertension

10. Melatonin and drug interaction

11. Melatonin and autoimmune diseases

12. Melatonin and COVID-19

13. Conclusions

\section{Introduction}

Melatonin, or N-acetyl-5-methoxy-tryptamine, was discovered by Aaron B. Lerner and colleagues in 1958 and was initially thought to change the skin color of frogs, and thus was considered to be associated with human skin disorders, such as vitiligo (1). However, later investigations revealed that melatonin cannot treat disruptions in skin pigmentation.

Melatonin is mainly produced by the pineal gland and secreted into the blood (2). Melatonin secretion is affected by the circadian rhythm, namely the dark light cycle. Artificial illumination during the night can decrease the natural release of melatonin and thus can disrupt the body's internal circadian rhythm with consecutive sleep disorders and immunity (2). It has been reported that melatonin 
plays important roles in various biological processes, including sleep, ageing, stress response and immunity (3). Although skepticism exists in the scientific community regarding melatonin as a 'cure for all', previous studies have reported the benefits of melatonin supplementation, such as antioxidant, analgesic and anxiolytic effect, thus slowing age-related diseases $(1,3,4)$.

A well-known role of melatonin remains in the treatment of insomnia. Clinical studies have revealed the role of melatonin in significantly improving the quality and depth of sleep at night, especially in patients with schizophrenia, traumatic brain injury and insomnia associated with other comorbidities, such as Alzheimer's disease, cancer, cardiovascular disease, diabetes and obesity (5).

In addition, sales of exogenous melatonin have increased in recent years (6). Melatonin is available without a prescription in numerous countries, and is sold in the form of capsules, tablets with sublingual dissolution, syrup or transdermal patches (2). However, there are concerns regarding the long-term use of melatonin in the elderly despite its low side effect profile and low potential for abuse. These concerns also stem from inappropriate dosing and use in specific clinical situations, such as an adjuvant in benzodiazepine dose-reduction schemes, where there are insufficient clinical studies to support efficacy $(7,8)$.

\section{Literature review methodology}

Here, an updated review of clinical trials and theoretical considerations published between 1980-2021 are discussed, which focus on the role of melatonin in sleep regulation, pathophysiology of inflammatory and cardiovascular diseases, regulating stress levels and the possibility of complementary therapy in Coronavirus 2019 infection (COVID-19). Databases, such as Elsevier (https://www.eu.elsevierhealth.com/medicine-and-surgery), PubMed (https://pubmed.ncbi.nlm.nih.gov), ScienceDirect Freedom Collection(https://www.sciencedirect. com) and Medline (https://www.medline.com)were used for data collection, by introducing the term 'melatonin' alone or in combination.

\section{Melatonin physiology}

Melatonin is a hormone secreted by the pineal gland under nerve modulation of the suprachiasmatic nucleus (9). Although melatonin is predominantly secreted by the pineal gland in mammals, some studies have reported that melatonin is produced in most cells, tissues and organs (9-11). Melatonin or $\mathrm{N}$-acetyl-5-methoxytryptamine is an acetamide, synthesized from tryptophan, with the intermediate chemical compound serotonin and N-Acetylserotonin (10). Melatonin receptors are expressed in the brain, cardiovascular system, retina of the eye, liver and gallbladder, kidney, colon and skin, suggesting its role as an immunological adjuvant, an antioxidant, a radical scavenger, an anticonvulsant, and a central nervous system depressant (12). There are three types of melatonin receptors, MT1, MT2 and MT3. Activation of receptors MT1 and MT2 helps promote sleep, modulates locomotor activity and regulates circadian rhythm (12). The MT3 receptor is best known for its detoxification role as a quinine reductase 2 , and is found in the heart, liver, intestine, muscle, kidney and fat tissues $(12,13)$.

\section{Dosage and side effects of melatonin}

The maximal effective doses of melatonin range from 0.5-10.0 mg, although some studies have suggested that effect doses range from 1-6 mg (14). Higher than physiological concentrations may cause desensitization of melatonin receptors, thus others have recommend low doses ranging from $0.3-2.0 \mathrm{mg}(14,15)$. Notably, the European Food Safety Authority recommends the use of maximum doses of $0.3-1.0 \mathrm{mg}$ (15). However, further studies are required to identify the minimal effective dose.

Administration timing is also important as melatonin phase-shifting effects are only exerted only when a response phase curve is produced (16). Melatonin elimination half-life is $1-2 \mathrm{~h}$, and bioavailability is $1-74 \%$, which is highly variable with formulation and dose. Different melatonin formulations are available, such as extended-release, immediate-release, combined immediate and extended-release (16). Metabolization predominantly occurs in the liver (90\%), where the CYP1A2 enzyme is mainly involved (16). The molecular mechanism by which melatonin secretion decreases with age remains unclear, and as melatonin supplementation may imply long-term use, there are concerns with regards to the side effects in certain groups of the population. The most common side effects are headaches, nausea and dizziness (17). In the elderly, exogenous melatonin may decrease blood pressure and cause hypothermia (17). The National Agency for the Safety of Medicines and Health Products from France published in 2016 listed 200 side effects associated with the use of melatonin, which was reported between 1985 and 2016, of which 43\% were neurological disorders (convulsion, syncope and headache), $24 \%$ were psychiatric disorders (anxiety and depression), 19\% were skin disorders (rashes and maculopapular rashes) and $19 \%$ were digestive problems (constipation, nausea and acute pancreatitis) (18). Currently, over the counter melatonin supplements are extensively used for their purported benefits associated with insomnia or insomnia caused by stress (19). These supplements often contain vitamins and micronutrients to increase the effect of melatonin (19). The most common supplements are magnesium and B complex vitamins, including B12 and B6 $(19,20)$. In addition to the various benefits of magnesium, such as preventing migraines, anti-inflammatory effect, increasing exercise performance, reducing the risk of developing type 2 diabetes, lowering blood pressure, it also reduces the risk of depression, which is a common cause of sleep disorders (21-23).

\section{Melatonin and insomnia}

Variations in sleep-wake patterns are amid the consequences of biological ageing $(24,25)$. Insomnia, defined as the inability to initiate or continue sleep with significant discomfort experienced during the next day (Diagnostic and Statistical Manual of Mental Disorders, 4th edition), is estimated to affect $\sim 30 \%$ of people $>55$ years (25). There is an age-related decrease in cerebral sleep regulation depending on circadian 
rhythm, which is associated with melatonin secretion (26). In people $>55$ years, who suffer from lack of sleep, melatonin production is much lower compared with healthy individuals without sleep disorders (25-28). When dealing with insomnia there is a need to assess a plethora of factors that can cause it, such as chronic medical conditions (Parkinson's disease, dementia, schizophrenia, depression, chronic obstructive pulmonary disease, congestive heart failure and pain) and concomitant medication (29). Several medicines favor or cause insomnia, such as selective serotonin reuptake inhibitors, dopamine agonists, antipsychotics, theophylline, anticonvulsants, decongestants, $\beta$-agonists, antihypertensive drugs ( $\alpha$-agonists and $\beta$-blockers), diuretics, thyroid hormone, steroids, caffeine, alcohol and niacin $(29,30)$. Melatonin and melatonin agonists are considered safer than benzodiazepines and nonbenzodiazepines $(31,32)$. Melatonin does not cause withdrawal or dependence symptoms, or a cognitive decline. However, there are contradictory studies, suggesting that cognitive decline in benzodiazepines users may be due to prodromal symptoms caused by preclinical dementia processes (32). Thus, melatonin is considered a safer alternative in treating insomnia (31-34). For sleep onset insomnia, American Academy of Sleep Medicine recommended $\mathrm{r}$ amelteon, a melatonin receptor agonist, which has no reported adverse effects (35).

\section{Melatonin and skin ageing}

As life expectancy and the percentage of the elderly population continues to increase ( $>65$ years), the risk of age-related diseases also continues to increase (36-38). It is suggested that there may be an association between longer life expectancy and disability (38). Therefore, ageing as a physiological process implies a series of sensory changes, muscle strength and fat changes, somatic disease, immunosenescence, urological changes, multiple chronic conditions (cardiovascular disease, hypertension, cancer, osteoarthritis diabetes mellitus and osteoporosis), physical function changes (mobility disability in activities of daily living), and psychological and cognitive changes, including minimal hepatic encephalopathy (38). Physiological brain ageing is portrayed by significant biochemical and structural changes and by the imbalance among different neurotransmitters and neuromodulators (36-38). Previous studies have reported that melatonin secretion is also affected. Age-related melatonin decrease may be based on different mechanisms, such as degeneration of the suprachiasmatic nucleus or neural pathways of transmission to the pineal gland that occurs in neurodegenerative disorders (39-41). Another study suggested that $24 \mathrm{~h}$ synthesis of melatonin is not significantly modified in normal ageing instead nocturnal peak serum concentration of melatonin may decrease (42). The skin a significant extrapineal site of melatonin synthesis and activity considering that important enzymes are present in skin cells and can independently produce melatonin (43-45). Ageing of the skin is a complicated mechanism, which happens over several years in a human's lifetime (46-50). Several environmental conditions hasten ageing; thus, plentiful research within dermato-endocrinology are being performed to identify efficient anti-ageing agents using indole melatonin (51). It has been reported that melatonin has powerful antioxidative properties and indispensable protective outcomes in different types of cells (skin epithelium, hair follicles, keratinocytes, melanocytes and fibroblasts) $(47,48)$. Thus, melatonin at physiological or pharmacologically supplemented levels acts as a cellular and tissue protector (46-51).

\section{Melatonin and UV protection}

The human body has a system of genes that regulate its activity according to the circadian rhythm $(52,53)$. Several cells in the body express these genes and adapt their metabolism via interdependent feedback loops of transcription and translation (53). Thus, this clock gene family, impose a homeostatic circadian rhythm (53). Clinical studies have demonstrated that alterations in these mechanisms can lead to increased skin lesions, which are associated with increased production and accumulation of reactive oxygen species (ROS) (54). In vitro studies on murine fibroblast cultures have reported associations between oxidative stress and clock gene reset (55). Increases in inflammatory markers have also been reported in conjunction with clock gene desynchronizations in skin cells (53). Melatonin plays a direct role in controlling the expression of the PER1 clock gene, and natural secretion of melatonin follows a circadian rhythm, which increases at night and decreases during the day (53). Melatonin secretion is receptive to light, thus variations in the light/dark cycle generate considerable changes in melatonin release (53). Aging is associated with increased oxidative stress in most cells; further studies are required to elucidate the molecules involved in triggering and maintaining this increased oxidative stress (56).

Under the effect of ultraviolet rays (UVR), ROS instantly develop in skin cells, participating in the degradation of nucleic acids, proteins and lipids (56). It has been demonstrated that the effect between UVR and type B ultraviolet (UVB) is mostly absorbed by the epidermis, which causes harmful effects on keratinocyte DNA, resulting in cellular apoptosis $(57,58)$. It has been reported that UVB acts on dermal fibroblasts and is involved in the process of accelerating aging (58). The genome repair system, after UVB exposure, is more effective in keratinocytes compared with fibroblasts, which makes them more resistant to UVB (58-61). The dermis absorbs most of the ultraviolet A (UVA), and they are responsible for aging of the skin, particularly by apoptosis of fibroblasts, but also by apoptosis of keratinocytes when the skin is exposed to high doses of UVA (58).

With regards to the cellular destruction caused by UV, melatonin neutralizes the production of ROS, which reduces mitochondrial and DNA degradation (60). It has been reported that melatonin can prevent sun damage when it reaches optimal intracellular levels prior to UV irradiation (62-65). The production of free radicals in the skin cells, under UV conditions, is a prompt event immediately after UV irradiation (66). Thus, it is suggested that oxidative stress that increases all known destructive aspects of the skin can be counterbalanced by the antioxidant effect of melatonin, in the presence of optimal intracellular concentrations at the time of UV exposure $(57,60,67,68)$. Collectively, these mechanisms suggest a significant UV damage protection mechanism for melatonin. However, whether melatonin protects against purported drug-induced cancers, such as those arising from tetracyclines and hydrochlorothiazide, remains unclear $(69,70)$. 


\section{Melatonin and Bateman purpura}

Actinic purpura is a dermatological condition described by Batermanin 1918, which is common in the elderly (71). It is a benign condition of the dermal connective tissues, which is caused by sun exposure (72). It is also known as the senile purple Bateman and appears in the form of dark purple spots on regions predominantly exposed to the sun, including the dorsal part of the hands and the extension surface of the forearm (71-73). Chronic exposure to solar UV is one of the central environmental aspects that can hasten the ageing process, followed by progressive deterioration of epidermal stem cell function (74).

Melatonin levels decrease with age, causing the skin's antioxidant capacity to decrease $(50,73,74)$. The decrease in cellular melatonin levels is associated with alteration of the clock genes that regulate cell circadian rhythm (75-77). Exposure of the skin to solar radiation intensifies oxidative stress (77). An in vitro study reported that MT-1 receptor levels in human fibroblasts are variable with age and that temporary suppression of the melatonin receptor increases $\mathrm{H}_{2} \mathrm{O}_{2}$ production and attenuates UV-induced DNA destruction in human skin fibroblast culture (50). Melatonin directly defends mitochondria by eliminating ROS and indirectly defends mitochondria by stabilizing the mitochondrial membrane potential and maintaining mitochondrial homeostasis in UV-exposed keratinocyte cultures $(66,50,75)$.

The most important effects of melatonin are the restriction of tyrosinase production and activation of melanocytes in the epidermis (76). Based on evidence from clinical trials demonstrating the role of melatonin and its metabolites, cytoprotective and antiaging, it is suggested that topical application of exogenous melatonin and/or its metabolites can be an effective future approach against skin aging (77-79).

\section{Melatonin and hypertension}

Melatonin secretion begins immediately after dark, reaches maximum secretion in the middle of the night and gradually decreases until sunrise (80). Reduced melatonin production during the night is common in patients with severe hypertension and coronary heart disease (81). As a metabolite, melatonin has a half-life of 40-50 min, and after a fast-release oral dose of exogenous melatonin, peak serum concentrations reached 20-30 $\mathrm{min}$ after ingestion, are sustained for $90 \mathrm{~min}$, and then rapidly decrease (82-85). Fast-release melatonin pharmaceutical formulations are effective in the first half of the night and completely ineffective in the second half of the night (82). Slow-release formulations manage to maintain optimal concentrations throughout the night if the dose is higher (82-85).

Several clinical trials have reported an association between melatonin levels, heart rate and blood pressure (82-85). A previous study demonstrated the role of melatonin in lowering blood pressure in a group of essential hypertensive patients and a crossover, placebo-controlled study in a group of healthy young normotensive subjects found a weak hypotensive effect following melatonin administration associated, with a decrease in heart rate during the day (86-88). Following pinealectomy, an improvement in vascular reactivity to vasoconstrictive agents was observed (89). The potential pathophysiological mechanisms by which melatonin influences blood pressure are as follows: A direct effect on nerve centers, low catecholamine concentrations, and antioxidant effect and relaxation of smooth muscle in blood vessels (86). Some studies have reported that patients with coronary heart disease, particularly those at higher risk of myocardial infarction and/or sudden death, have low levels of melatonin $(83,90,91)$. Another study demonstrated that patients with high levels of low-density lipoprotein (LDL) cholesterol have low melatonin secretion (90). Melatonin lowers cholesterol formation and LDL accumulation in the serum, and changes the fatty acid composition of rat plasma (90). Further studies are required to determine the role of melatonin in cardiovascular hemodynamics, lipid metabolism and the potential influence on cardiovascular morbidity and mortality (87-91).

\section{Melatonin and drug interaction}

Cardiovascular disease is common in the elderly, and $\beta$-adrenergic receptor blockers are often used in therapy (92). Lower concentrations of melatonin in serum and 6-sulfatoximelatonin in urine were observed in the elderly compared with young people $(93,94)$. Vascular melatoninergic receptors are associated with the vasoconstrictor or vasodilating effects of melatonin (95). Norepinephrine stimulates the formation and release of melatonin through $\beta 1$-adrenoceptors and $\alpha-1$ adrenoceptors (96). Thus, $\beta$-blockers decrease melatonin production by distinctly inhibiting $\beta-1$ adrenergic receptors (96). A total of two placebo-controlled studies in hypertensive patients reported the association between melatonin levels in nocturnal urine and sleep disorders as an adverse effect of $\beta$-blockers. The studies concluded that the side effects of sleep disorders and nightmares during $\beta$-blockade are associated with a decrease in nocturnal melatonin levels. Thus, taking melatonin at bedtime can prevent this common side effect of $\beta$-blockers $(92,97,98)$.

Previous studies have reported that melatonin inhibits glucocorticoid synthesis in different species $(99,100)$. Melatonin exerts inhibitory effects on adrenocorticotropin (ACTH) secretion in the anterior pituitary gland and adrenal cortisol production via various mechanisms (for example, suppress ACTH secretion via BMP-4 in corticotropic cells) (101-104). It has also been demonstrated that, under the control of ACTH, melatonin improves aldosterone production by cooperating with activation in adrenal cells (105). Melatonin decreases the toxicity caused by glucocorticoids, which was observed during treatment with dexamethasone in combination with neurotoxins. The mechanism of this action is the ability of the melatonin to reduce glucocorticoid receptor nuclear translocation (106).

\section{Melatonin and autoimmune diseases}

Melatonin can adjust immune responses by modulating the Th1/Th2 balance and cytokine secretion (107). Autoimmune diseases are abroad spectrum of disorders that include inequality of T-cell subgroups, extensive inflammation and successive tissue damage. In the autoimmune mechanism, modified Th1 and Th17 cells can produce proinflammatory cytokines, 
interferon $\gamma$ and IL-17 (108). Previous studies have suggested the potential of melatonin to modulate the humoral and cellular immune response, cell proliferation and levels of immune mediators. Pharmacological addition of melatonin immediately influences T-cell differentiation, regulates the balance between pathogenic and regulatory T-cells and modulates the secretion of proinflammatory cytokines $(107,108)$.

The pathophysiological mechanisms involved in allergic or atopic diseases include the activation of Th2 cells and consequently, the production of $\operatorname{IgE}$ antibodies (109). Autoimmune diseases involve the alteration of the mechanisms of maintaining self-tolerance in B lymphocytes, T lymphocytes or both, identification of autoantigens by lymphocyte, and overactivation of these cells by excessive proliferation and differentiation into effector cells, with consequences in tissue damage (107). Melatonin treatment has been studied in atopic diseases and autoimmune diseases in animal and human models (109). Thus, melatonin may serve as a potential new therapeutic object, leading to favorable circumstances for the treatment of autoimmune diseases (109). Melatonin may also provide an explanation as to why certain therapeutic strategies provide benefits in lichen planus (an autoimmune disease), while improving the general sense of well-being, including sleep (110).

\section{Melatonin and COVID-19}

COVID-19, caused by Coronavirus 2 (SARS-CoV-2), was first cited as cases of pneumonia of unknown cause in December 2019 in Wuhan, China. Today, we are witnessing the most important contemporary pandemic, a pathology that has restructured all health systems worldwide, and is estimated to cause $>200$ million cases and 4 million deaths worldwide by September 2021 (111). The variability of clinical forms of COVID-19, from asymptomatic forms to severe forms with death, opened the discussion about the variability of the host immune response to viral infection. The predominance of severe forms in the elderly has also opened the discussion about the vulnerability of these hosts, in terms of the immune system, vascular fragility and even low melatonin levels in the elderly. The response to viral infection is associated with oxidative stress and the response of mononuclear cells in peripheral blood (112). A study by researchers at Oxford University and the Oxford Health Center for Biomedical Research reported that nearly $1 / 5$ people who had COVID-19 were diagnosed with a psychiatric disorder, such as insomnia within 3 months of testing positive for SARS-CoV-2 $(113,114)$. Several clinical studies highlight the antiviral, antioxidant and anti-inflammatory properties of melatonin in respiratory viral infections. Melatonin has been reported to play a role in reducing vessel permeability, sedation, decreasing agitation and improving sleep quality. These valuable features of melatonin open the prospect of clinical trials assessing the efficacy of melatonin in COVID-19 (115-118).

\section{Conclusions}

Melatonin, in addition to its best-known effect in combating insomnia, may be an adjunct in anticonvulsant therapy, supporting the immune system and preventing skin aging.
Its role as an antioxidant and free radical scavenger can be useful in topical application prior to UV exposure to prevent skin lesions caused by UV and skin aging. Melatonin intervenes in the regulation of blood pressure and particularly in combating the adverse effect of $\beta$-blockers, namely insomnia. The involvement of melatonin in modulating the secretion of inflammatory cytokines means it exerts antiviral properties.

Further clinical trials are required to verify the safety and potential side effects of melatonin at optimal doses, particularly in the elderly, where long-term use may be unavoidable. The potential use of melatonin as an adjunct in the treatment of mental, neurodegenerative, metabolic, cardiovascular disorders, reproductive dysfunction, neoplasms and acute or chronic infections should also be studied.

\section{Acknowledgements}

Not applicable.

\section{Funding}

The present study was academically supported by the 'Dunarea de Jos' University of Galati, Romania, via the Multidisciplinary Integrated Center of Dermatological Interface Research center.

\section{Availability of data and materials}

Not applicable.

\section{Authors' contributions}

LA, LB, CRP, LN, SF, IAS and DP performed the literature review. LA, LB, AN, CLM and ALT made substantial contributions to the conception and design of the present study. LA, LB, AC, ABC and ALT supervised the present study and revised the manuscript for important intellectual content. Data authentication is not applicable. All authors have read and approved the final manuscript.

\section{Ethics approval and consent to participate}

Not applicable.

\section{Patient consent for publication}

Not applicable.

\section{Competing interests}

The authors declare that they have no competing interests.

\section{References}

1. Vural EM, van Munster BC and de Rooij SE: Optimal dosages for melatonin supplementation therapy in older adults: A systematic review of current literature. Drugs Aging 31: 441-451, 2014.

2. Posadzki PP, Bajpai R, Kyaw BM, Roberts NJ, Brzezinski A, Christopoulos GI, Divakar U, Bajpai S, Soljak M, Dunleavy G, et al: Melatonin and health: An umbrella review of health outcomes and biological mechanisms of action. BMC Med 16: 18, 2018. 
3. Navarro-Alarcon M, Ruiz-Ojeda FJ, Blanca-Herrera RM and Agil A: Antioxidant activity of melatonin in diabetes in relation to the regulation and levels of plasma $\mathrm{Cu}, \mathrm{Zn}, \mathrm{Fe}, \mathrm{Mn}$, and $\mathrm{Se}$ in Zucker diabetic fatty rats. Nutrition 29: 785-789, 2013.

4. Yousaf F, Seet E, Venkatraghavan L, Abrishami A and Chung F: Efficacy and safety of melatonin as an anxiolytic and analgesic in the perioperative period: A qualitative systematic review of randomized trials. Anesthesiology 113: 968-976, 2010.

5. Gray $\mathrm{C}$ and Ryce A: Melatonin for the treatment of insomnia: A review of clinical effectiveness, cost-effectiveness, and guidelines. CADTH (CADTH rapid response report: summary with critical appraisal), [Internet]. Canadian Agency for Drugs and Technologies in Health, Ottawa, ON, 2019. https://www.ncbi. nlm.nih.gov/books/NBK544670/. February 22, 2019.

6. Grigg-Damberger MM and Ianakieva D: Poor quality control of over-the-counter melatonin: What they say is often not what you get. J Clin Sleep Med 13: 163-165, 2017.

7. Wright A, Diebold J, Otal J, Stoneman C, Wong J, Wallace C and Duffett M: The effect of melatonin on benzodiazepine discontinuation and sleep quality in adults attempting to discontinue benzodiazepines: A systematic review and meta-analysis. Drugs Aging 32: 1009-1018, 2015.

8. Jarzynka MJ, Passey DK, Johnson DA, Konduru NV, Fitz NF, Radio NM, Rasenick M, Benloucif S, Melan MA and Witt-Enderby PA: Microtubules modulate melatonin receptors involved in phase-shifting circadian activity rhythms: In vitro and in vivo evidence. J Pineal Res 46: 161-171, 2009.

9. Jou MJ, Peng TI, Hsu LF, Jou SB, Reiter RJ, Yang CM, Chiao CC, Lin YF and Chen CC: Visualization of melatonin's multiple mitochondrial levels of protection against mitochondrial $\mathrm{Ca}(2+)$-mediated permeability transition and beyond in rat brain astrocytes. J Pineal Res 48: 20-38, 2010.

10. Acuña-Castroviejo D, Escames G, Venegas C, Díaz-Casado ME Lima-Cabello E, López LC, Rosales-Corral S, Tan DX and Reiter RJ: Extrapineal melatonin: Sources, regulation, and potential functions. Cell Mol Life Sci 71: 2997-3025, 2014.

11. Tan DX and Reiter RJ: Mitochondria: The birth place, battle ground and the site of melatonin metabolism in cells. Melatonin Res 2: 44-66, 2019.

12. Emet M, Ozcan H, Ozel L, Yayla M, Halici $Z$ and Hacimuftuoglu A: A review of melatonin, its receptors and drugs. Eurasian J Med 48: 135-141, 2016.

13. Andersen LP, Werner MU, Rosenberg J and Gögenur I: A systematic review of peri-operative melatonin. Anaesthesia 69: 1163-1171, 2014

14. St Louis EK and Boeve BF: REM sleep behavior disorder: Diagnosis, clinical implications, and future directions. Mayo Clin Proc 92: 1723-1736, 2017.

15. Agostoni C, Bresson JL, Fairweather-Tait S, et al: EFSA panel on dietetic products, N. and allergies. Scientific opinion on the substantiation of a health claim related to melatonin and reduction of sleep onset latency (ID 1698, 1780, 4080) pursuant to Article 13(1) of Regulation (EC) No 1924/2006. EFSA J 9 : 2241,2011

16. Ma X, Idle JR, Krausz KW and Gonzalez FJ: Metabolism of melatonin by human cytochromes p450. Drug Metab Dispos 33: 489-494, 2005

17. Zhdanova IV, Wurtman RJ, Regan MM, Taylor JA, Shi JP and Leclair OU: Melatonin treatment for age-related insomnia. J Clin Endocrinol Metab 86: 4727-4730, 2001

18. Besag FMC, Vasey MJ, Lao KSJ and Wong ICK: Adverse events associated with melatonin for the treatment of primary or secondary sleep disorders: A systematic review. CNS Drugs 33: $1167-1186,2019$

19. Abbasi B, Kimiagar M, Sadeghniiat K, Shirazi MM, Hedayati M and Rashidkhani B: The effect of magnesium supplementation on primary insomnia in elderly: A double-blind placebo-controlled clinical trial. J Res Med Sci 17: 1161-1169, 2012.

20. Akindele OO, Kunle-Alabi OT, Adeyemi DH, Oghenetega BO and Raji Y: Effects of vitamin E and melatonin on serum testosterone level in sleep deprived wistar rats. Afr J Med Med Sci 43: 295-304, 2014.

21. Nielsen FH: Magnesium, inflammation, and obesity in chronic disease. Nutr Rev 68: 333-340, 2010

22. Nutt D, Wilson S and Paterson L: Sleep disorders as core symptoms of depression. Dialogues Clin Neurosci 10: 329-336, 2008.

23. Hruby A, Meigs JB, O'Donnell CJ, Jacques PF and McKeown NM: Higher magnesium intake reduces risk of impaired glucose and insulin metabolism and progression from prediabetes to diabetes in middle-aged americans. Diabetes Care 37: 419-427, 2014.
24. Kass LS, Skinner P and Poeira F: A pilot study on the effects of magnesium supplementation with high and low habitual dietary magnesium intake on resting and recovery from aerobic and resistance exercise and systolic blood pressure. J Sports Sci Med 12: 144-150, 2013.

25. Lemoine P, Wade AG, Katz A, Nir T and Zisapel N: Efficacy and safety of prolonged-release melatonin for insomnia in middle-aged and elderly patients with hypertension: A combined analysis of controlled clinical trials. Integr Blood Press Control 5: 9-17, 2012.

26. Bliwise DL, King AC, Harris RB and Haskell WL: Prevalence of self-reported poor sleep in a healthy population aged 50-65. Soc Sci Med 34: 49-55, 1992.

27. Roth T: Insomnia: Definition, prevalence, etiology, and consequences. J Clin Sleep Med 3 (Suppl 5): S7-S10, 2007.

28. Roth T and Roehrs T: Insomnia: Epidemiology, characteristics, and consequences. Clin Cornerstone 5: 5-15, 2003.

29. Wolkove N, Elkholy O, Baltzan M and Palayew M: Sleep and aging: 1. Sleep disorders commonly found in older people. CMAJ 176: 1299-1304, 2007

30. Marin IM, Petropolou M, Baroiu L, Chirosca AC, Anghel L and Luca L: Schizophrenia and the family burden during the pandemic. BRAIN. Broad Research in Artificial Intelligence and Neuroscience 11: 89-97, 2020.

31. Hardeland R, Poeggeler B, Srinivasan V, Trakht I, Pandi-Perumal SR and Cardinali DP: Melatonergic drugs in clinical practice. Arzneimittelforschung 58: 1-10, 2008.

32. Zhang Y, Zhou XH, Meranus DH, Wang L and Kukull WA: Benzodiazepine use and cognitive decline in elderly with normal cognition. Alzheimer Dis Assoc Disord 30: 113-117, 2016.

33. Nader D and Gowing L: Is long-term benzodiazepine use a risk factor for cognitive decline? Results of a systematic review. J Addict 24: 1569456, 2020.

34. Baroiu L, Dumea E, Năstase F, Niculet E, Fotea S, Ciubara AB, Stefanopol IA, Nechita A, Anghel L and Ciubara A: Assessment of depression in patients with COVID-19. BRAIN. Broad Research in Artificial Intelligence and Neuroscience 12: 254-264, 2021.

35. Neubauer DN: A review of ramelteon in the treatment of sleep disorders. Neuropsychiatr Dis Treat 4: 69-79, 2008

36. Stefanopol IA, Miulescu M, Baroiu L, Anghele AD, Danila DM and Tiron Z: An unusual case of meckel diverticulitis misdiagnosed as an infected urachal cyst. Medicina 57: 495, 2021.

37. Voicu DF, Anghel L, Baroiu L and Stan D: About minimal hepatic encephalopathy. BRAIN. Broad Research in Artificial Intelligence and Neuroscience 11: 70-77, 2020

38. Sack RL, Lewy AJ, Erb DL, Vollmer WM and Singer CM Human melatonin production decreases with age. J Pineal Res 3: 379-388, 1986

39. Karasek M and Reiter RJ: Melatonin and aging. Neuro Endocrinol Lett 23 (Suppl 1): S14-S16, 2002

40. Skene DJ and Swaab DF: Melatonin rhythmicity: Effect of age and Alzheimer's disease. Exp Gerontol 38: 199-206, 2003.

41. Scholtens RM, van Munster BC, van Kempen MF and de Rooij SE: Physiological melatonin levels in healthy older people: A systematic review. J Psychosom Res 86: 20-27, 2016.

42. Fischer TW, Sweatman TW, Semak I, Sayre RM, Wortsman J and Slominski A: Constitutive and UV-induced metabolism of melatonin in keratinocytes and cell-free systems. FASEB J 20: 1564-1566, 2006

43. Slominski A, Pisarchik A, Semak I, Sweatman T, Wortsman J, Szczesniewski A, Slugocki G, McNulty J, Kauser S, Tobin DJ, et al: Serotoninergic and melatoninergic systems are fully expressed in human skin. FASEB J 16: 896-898, 2002.

44. Slominski A, Pisarchik A, Zbytek B, Tobin DJ, Kauser S and Wortsman J: Functional activity of serotoninergic and melatoninergic systems expressed in the skin. J Cell Physiol 196: 144-153, 2003.

45. Tan DX, Manchester LC, Terron MP, Flores LJ and Reiter RJ: One molecule, many derivatives: A never-ending interaction of melatonin with reactive oxygen and nitrogen species? J Pineal Res 42: 28-42, 2007

46. Reiter RJ and Tan DX: What constitutes a physiological concentration of melatonin? J Pineal Res 34: 79-80, 2003.

47. Reiter RJ, Tan DX and Maldonado MD: Melatonin as an antioxidant: Physiology versus pharmacology. J Pineal Res 39: 215-216, 2005.

48. Tan DX, Manchester LC, Hardeland R, Lopez-Burillo S, Mayo JC, Sainz RM and Reiter RJ: Melatonin: A hormone, a tissue factor, an autocoid, a paracoid, and an antioxidant vitamin. J Pineal Res 34: 75-78, 2003 
49. Kleszczynski K and Fischer TW: Melatonin and human skin aging. Dermatoendocrinol 4: 245-252, 2012.

50. Dong K, Goyarts E, Rella A, Pelle E, Wong YH and Pernodet N: Age associated decrease of MT-1 melatonin receptor in human dermal skin fibroblasts impairs protection against UV-induced DNA damage. Int J Mol Sci 21: 326, 2020.

51. Slominski A, Tobin DJ, Zmijewski MA, Wortsman J and Paus R: Melatonin in the skin: Synthesis, metabolism and functions. Trends Endocrinol Metab 19: 17-24, 2008.

52. Slominski A: Neuroendocrine activity of the melanocyte. Exp Dermatol 18: 760-763, 2009.

53. Matsui MS, Pelle E, Dong K and Pernodet N: Biological rhythms in the skin. Int J Mol Sci 17: 801, 2016.

54. Tamaru T, Hattori M, Ninomiya Y, Kawamura G, Varès G, Honda K, Mishra DP, Wang B, Benjamin I, Sassone-Corsi P, et al: ROS stress resets circadian clocks to coordinate pro-survival signals. PLoS One 8: e82006, 2013.

55. Bernerd F and Asselinau D: UVA exposure of human skin reconstructed in vitro induces apoptosis of dermal fibroblasts: Subsequent connective tissue repair and implication in photoaging. Cell Death Differ 5: 792-802, 1998.

56. Kleszczynski K, Hardkop LH and Fisher TW: Differential effects of melatonin as a broad range UV-damage preventive dermato-endocrine regulator. Dermatoendocrinol 3: 27-31, 2011

57. Fischer TW, Slominski A, Zmijewski MA, Reiter RJ and Paus R: Melatonin as a major skin protectant: From free radical scavenging to DNA damage repair. Exp Dermatol 17: 713-730, 2008

58. Izykowska I, Cegielski M, Gebarowska E, Podhorska-Okolow M, Piotrowska A, Zabel M and Dziegiel P: Effect of melatonin on human keratinocytes and fibroblasts subjected to UVA and UVB radiation in vitro. In Vivo 23: 739-745, 2009.

59. Aitken GR, Henderson JR, Chang SC, McNeil CJ and Birch-Machin MA: Direct monitoring of UV-induced free radical generation in HaCaT keratinocytes. Clin Exp Dermatol 32: 722-727, 2007.

60. D'Errico M, Lemma T, Calcagnile A, De Santis LP and Dogliotti E: Cell type and DNA damage-specific response to human skin cells to environmental agents. Mutat Res 614: 37-47, 2007.

61. Lee KS, Kim SJ, Ryoo YW and Kim BC: All-trans-retinoic acid down-regulates elastin promoter activity elevated by ultraviolet B irradiation in cultured skin fibroblasts. J Dermatol Sci 17: 182-189, 1998

62. Bangha E, Elsner P and Kistler GS: Suppression of UV-induced erythema by topical treatment with melatonin (N-acetyl-5-methoxytryptamine). A dose response study. Arch Dermatol Res 288: 522-526, 1996.

63. Dreher F, Denig N, Gabard B, Schwindt DA and Maibach HI Effect of topical antioxidants on UV-induced erythema formation when administered after exposure. Dermatology 198: 52-55, 1999.

64. Slominski AT, Zmijewski MA, Semak I, Kim TK, Janjetovic Z, Slominski RM and Zmijewski JW: Melatonin, mitochondria, and the skin. Cell Mol Life Sci 74: 3913-3925, 2017.

65. Dreher F, Gabard B, Schwindt DA and Maibach HI: Topical melatonin in combination with vitamins $\mathrm{E}$ and $\mathrm{C}$ protects skin from ultraviolet-induced erythema: A human study in vivo. $\mathrm{Br}$ J Dermatol 139: 332-339, 1998

66. Fischer TW, Zmijewski MA, Wortsman J and Slominski A: Melatonin maintains mitochondrial membrane potential and attenuates activation of initiator (casp-9) and effector caspases (casp-3/casp-7) and PARP in UVR-exposed HaCaT keratinocytes. J Pineal Res 44: 397-407, 2008.

67. Berbinschi S, Baroiu N, Teodor V and Oancea N: Profiling method of side mill for threading screw for dental implants. Adv Mat Res 837: 22-27, 2014

68. Baroiu N, Teodor VG, Berbinschi S, Susac F and Oancea N: New sharpening method and the behaviour of the multi-flute twist drill with curved cutting edge in machining operations. Indian J Eng Mater Sci 23: 357-369, 2016.

69. Tatu AL, Ciobotaru OR, Miulescu M, Buzia OD, Elisei AH Mardarea N, Diaconu C, Robu S and Nwabudike LC: Hydrochlorothiazide: Chemical structure, therapeutic, phototoxic and carcinogenetic effects in dermatology. Rev Chim 69 2110-2114, 2018

70. Nwabudike LC and Tatu AL: Response to-chronic exposure to tetracyclines and subsequent diagnosis for non-melanoma skin cancer in a large Mid-Western US population. J Eur Acad Dermatol Venereol 32: e159, 2018
71. Hafsi W, Masood S and Badri T: Actinic purpura. In: StatPearls [Internet]. StatPearls Publishing, Treasure Island, FL, 2021.

72. Ceilley RI: Treatment of actinic purpura. J Clin Aesthet Dermatol 10: 44-50, 2017.

73. Gerber PA, Buhren BA, Schrumpf H, Hevezi P, Bölke E, Sohn D, Jänicke RU, Belum VR, Robert C, Lacouture ME and Homey B: Mechanisms of skin aging induced by EGFR inhibitors. Support Care Cancer 24: 4241-4248, 2016.

74. Zouboulis CC, Adjaye J, Akamatsu H, Moe-Behrens G and Niemann C: Human skin stem cells and the ageing process. Exp Gerontol 43: 986-997, 2008

75. Baroiu N, Berbinschi S, Teodor VG, Susac F and Oancea N: The complementary graphical method used for profiling side mill for generation of helical surface. Modern technologies in industrial engineering. IOP Conference Series Materials Science and Engineering 227: 012013, 2017.

76. Kim TK, Lin Z, Tidwell WJ, Li W and Slominski AT: Melatonin and its metabolites accumulate in the human epidermis in vivo and inhibit proliferation and tyrosinase activity in epidermal melanocytes in vitro. Mol Cell Endocrinol 404: 1-8, 2015.

77. Milani $M$ and Sparavigna A: Antiaging efficacy of melatonin-based day and night creams: A randomized, split-face, assessor-blinded proof-of-concept trial. Clin Cosmet Investig Dermatol 11: 51-57, 2018

78. Sagan D, Stepniak J, Gesing A, Lewinski A and KarbownikLewinska M: Melatonin reverses the enhanced oxidative damage to membrane lipids and improves skin biophysical characteristics in former-smokers-A study in postmenopausal women. Ann Agric Environ Med 24: 659-666, 2017

79. Bocheva G, Slominski RM and Slominski AT: Neuroendocrine aspects of skin aging. Int J Mol Sci 20: 2798, 2019.

80. Grossman E, Laudon M and Zisapel N: Effect of melatonin on nocturnal blood pressure: Meta-analysis of randomized controlled trials. Vasc Health Risk Manag 7: 577-584, 2011.

81. Jonas M, Garfinkel D, Zisapel N, Laudon M and Grossman E: Impaired nocturnal melatonin secretion in non-dipper hypertensive patients. Blood Press 12: 19-24, 2003.

82. Zeman M, Dulková K, Bada V and Herichová I: Plasma melatonin concentrations in hypertensive patients with the dipping and non-dipping blood pressure profile. Life Sci 76: 1795-1803, 2005.

83. Sakotnik A, Liebmann PM, Stoschitzky K, Lercher $P$, Schauenstein K, Klein W and Eber B: Decreased melatonin synthesis in patients with coronary artery disease. Eur Heart J 20: 1314-1317, 1999

84. Waldhauser F, Waldhauser M, Lieberman HR, Deng MH, Lynch HJ and Wurtman RJ: Bioavailability of oral melatonin in humans. Neuroendocrinology 39: 307-313, 1984

85. Aldhous M, Franey C, Wright J and Arendt J: Plasma concentrations of melatonin in man following oral absorption of different preparations. Br J Clin Pharmacol 19: 517-521, 1985.

86. Paulis L and Simko F: Blood pressure modulation and cardiovascular protection by melatonin: Potential mechanisms behind. Physiol Res 56: 671-684, 2007.

87. Birau N, Peterssen U, Meyer C and Gottschalck J: Hypotensive effect of melatonin in essential hypertension. IRCS Med Sci 9: 906, 1981.

88. Lusardi P, Preti P, Savino S, Piazza E, Zoppi A and Fogari R: Effect of bedtime melatonin ingestion on blood pressure of normotensive subjects. Blood Press Monit 2: 99-103, 1997.

89. Cunnane SC, Manku MS, Oka M and Horrobin DF: Enhanced vascular reactivity to various agents following pinealectomy in the rats: Role of melatonin. Can J Physiol Pharmacol 58: 287-293, 1980.

90. Koziróg M, Poliwczak AR, Duchnowicz P, Koter-Michalak M, Sikora J and Broncel M: Melatonin treatment improves blood pressure, lipid profile, and parameters of oxidative stress in patients with metabolic syndrome. J Pineal Res 50: 261-266, 2011

91. Sewerynek E: Melatonin and the cardiovascular system. Neuro Endocrinol Lett 23 (Suppl 1): S79-S83, 2002.

92. Fares A: Night-time exogenous melatonin administration may be a beneficial treatment for sleeping disorders in beta blocker patients. J Cardiovasc Dis Res 2: 153-155, 2011.

93. Altun A and Ugur-Altun B: Melatonin: Therapeutic and clinical utilization. Int J Clin Pract 61: 835-845, 2007.

94. Bradley HA, Wiysonge CS, Volmink JA, Mayosi BM and Opie LH: How strong is the evidence for use of beta-blockers as first-line therapy or hypertension? Systematic review and meta-analysis. J Hypertens 24: 2131-2141, 2006. 
95. Scalbert E, Guardiola-Lemaître B and Delagrange P: Melatonin and regulation of the cardiovascular system. Therapie 53: 459-465, 1998 (In French).

96. Brismar K, Hylander B, Eliasson K, Rössner S and Wetterberg L: Melatonin secretion related to side-effects of beta-blockers from the central nervous system. Acta Med Scand 223: 525-530, 1988

97. Brismar K, Mogensen L and Wetterberg L: Depressed melatonin secretion in patients with nightmares due to beta-adrenoceptor blocking drugs. Acta Med Scand 221: 155-158, 1987.

98. Tatu AL, Elisei AM, Chioncel V, Miulescu M and Nwabudike LC: Immunologic adverse reactions of $\beta$-blockers and the skin. Exp Ther Med 18: 955-959, 2019.

99. KomatsubaraM,HaraT,Hosoya T,TomaK,Tsukamoto-YamauchiN, Iwata N, Inagaki K, Wada J and Otsuka F: Melatonin regulates catecholamine biosynthesis by modulating bone morphogenetic protein and glucocorticoid actions. J Steroid Biochem Mol Biol 165: 182-189, 2017.

100. Torres-Farfan C, Richter HG, Rojas-Garcia P, Vergara M, Forcelledo ML,Valladares LE, Torrealba F, Valenzuela GJ and Serón-Ferré M: mt1 Melatonin receptor in the primate adrenal gland: Inhibition of adrenocorticotropin-stimulated cortisol production by melatonin. J Clin Endocrinol Metab 88: 450-458, 2003.

101. Campino C, Valenzuela F, Arteaga E, Torres-Farfan C, Trucco C, Velasco A, Guzmán S and Serón-Ferré M: Melatonin reduces cortisol response to ACTH in humans. Rev Med Chil 136: 1390-1397, 2008 (In Spanish).

102. Torres-Farfan C, Valenzuela FJ, Mondaca M, Valenzuela GJ, Krause B, Herrera EA, Riquelme R, Llanos AJ and Seron-Ferre M: Evidence of a role for melatonin in fetal sheep physiology: Direct actions of melatonin on fetal cerebral artery, brown adipose tissue and adrenal gland. J Physiol 586 4017-4027, 2008

103. Campino C, Valenzuela FJ, Torres-Farfan C, Reynolds HE, Abarzua-Catalan L, Arteaga E, Trucco C, Guzman S, Valenzuela GJ and Seron-Ferre M: Melatonin exerts direct inhibitory actions on ACTH responses in the human adrenal gland. Horm Metab Res 43: 337-342, 2011.

104. Tsukamoto N, Otsuka F, Ogura-Ochi K, Inagaki K, Nakamura E, Toma K, Terasaka T, Iwasaki Y and Makino H: Melatonin receptor activation suppresses adrenocorticotropin production via BMP-4 action by pituitary AtT20 cells. Mol Cell Endocrinol 375: 1-9, 2013.

105. Hara T, Otsuka F, Tsukamoto-Yamauchi N, Inagaki K, Hosoya T, Nakamura E, Terasaka T, Komatsubara $\mathrm{M}$ and Makino $\mathrm{H}$ Mutual effects of melatonin and activin on induction of aldosterone production by human adrenocortical cells. J Steroid Biochem Mol Biol 152: 8-15, 2015.

106. Quiros I, Mayo JC, Garcia-Suarez O, Hevia D, Martin V, Rodríguez C and Sainz RM: Melatonin prevents glucocorticoid inhibition of cell proliferation and toxicity in hippocampal cells by reducing glucocorticoid receptor nuclear translocation. J Steroid Biochem Mol Biol 110: 116-124, 2008.
107. Zhao CN, Wang P, Mao YM, Dan YL, Wu Q, Li XM, Wang DG, Davis $\mathrm{C}, \mathrm{Hu} \mathrm{W}$ and Pan HF: Potential role of melatonin in autoimmune diseases. Cytokine Growth Factor Rev 48: 1-10, 2019.

108. Niculet E, Chioncel V, Elisei AM, Miulescu M, Buzia OD, Nwabudike LC, Craescu M, Draganescu M, Bujoreanu F, Marinescu E, et al: Multifactorial expression of IL-6 with update on COVID-19 and the therapeutic strategies of its blockade. Exp Ther Med 21: 263, 2021.

109. Calvo JR and Maldonado MD: The role of melatonin in autoimmune and atopic diseases. AIMS Mol Sci 3: 158-186, 2016.

110. Nwabudike LC, Miulescu M and Tatu AL: Case series of an alternative therapy for generalised lichen planus: Four case studies. Exp Ther Med 18: 943-948, 2019.

111. Huang C, Wang Y, Li X, Ren L, Zhao J, Hu Y, Zhang L, Fan G, $\mathrm{Xu} \mathrm{J}, \mathrm{Gu} \mathrm{X}$, et al: Clinical features of patients infected with 2019 novel coronavirus in Wuhan, China. Lancet 395: 497-506, 2020.

112. Baroiu L, Dumitru C, Iancu A, Lese AC, Drăgănescu M, Baroiu N and Anghel L: COVID-19 impact on the liver. World J Clin Cases 9: 3814-3825, 2021

113. Juybari KB, Pourhanifeh MH, Hosseinzadeh A, Hemati K and Mehrzadi S: Melatonin potentials against viral infections including COVID-19: Current evidence and new findings. Virus Res 287: 198108, 2007.

114. Baroiu N, Baroiu L, Teodor VG and Ciocan TL: Gaphical method for profiling the side mill which generate helical flute of tungsten carbide dental cross cut bur. Rev Rom Mater 48: 131-139, 2018.

115. Shneider A, Kudriavtsev A and Vakhrusheva A: Can melatonin reduce the severity of COVID-19 pandemic? Int Rev Immunol 39: 153-162, 2020.

116. Parlakpinar H, Polat S and Acet HA: Pharmacological agents under investigation in the treatment of coronavirus disease 2019 and the importance of melatonin. Fundam Clin Pharmacol 35: $62-75,2021$

117. Tatu AL, Baroiu L, Fotea S, Anghel L, Polea ED, Nadasdy T, Chioncel V and Nwabudike LC: A working hypothesis on vesicular lesions related to COVID-19 infection, koebner phenomena type V, and a short review of related data. Clin Cosmet Investig Dermatol 14: 419-423, 2021.

118. Zhang R, Wang X, Ni L, Di X, Ma B, Niu S, Liu C and Reiter RJ: COVID-19: Melatonin as a potential adjuvant treatment. Life Sci 250: 117583, 2020.

(i) $($ This work is licensed under a Creative Commons Attribution-NonCommercial-NoDerivatives 4.0 International (CC BY-NC-ND 4.0) License. 